\title{
Criss-Crossing STEM Fields through Knowledge Building Discourse: an Explanatory Study
}

\author{
Ahmad Khanlari, Stacy Costa \\ a.khanlari@mail.utoronto.ca, stacy.costa@mail.utoronto.ca \\ University of Toronto
}

\begin{abstract}
Studies show that Knowledge Building discourses result in producing knowledge of value to others, and advancing the knowledge of the community. This explatory work in progress study aims to examine how knowledge building discourse on science can result exceeding expectations, so that not only the community knowledge about science advanced, but also students criss-cross STEM domains.
\end{abstract}

Keywords: Knowledge Building, STEM education

\section{INTRODUCTION}

The current Ontario curriculum focuses on predetermined outcomes and expectations; a set of skills and knowledge that students need to acquire. Students need new methods to engage in "Stemovation", innovative pedagogies in understand, question, and learn STEM disciplines. Knowledge Building pedagogy is a contrasting inculcation, that instead places expectations on students in a collaborative based endeavor, by discovering Knowledge in a community setting, by going beyond the predetermined outcomes.

Knowledge that may be out of reach for someone learning alone, but may be accessible if the learner has the support of peers or more knowledgeable others' (Van de Walle et al., 2014, p. 6). Knowledge Building is described as an idea-centered pedagogy with students as epistemic agents, creating knowledge through engaging in complex socio-cognitive interactions.. Knowledge Building turns high level agency to students and assumes that students should set their learning goals, engage in planning, and monitor and assess their work and idea coherence. Through extended Knowledge Building experience, students "crisscross the domain" scripts, rather than merely moving toward pre-specified learning objectives (scardamalia \& Bereiter, 2016). Criss-crossing the domains helps students to acquire the required knowledge to work in the multidisciplinary $21 \mathrm{st}$ century workplaces that are highly STEM (Science, Technology, Engineering, and Mathematics) based.

The purpose of this study is to examine how Knowledge Building within science can assist students to better criss-cross the STEM domains.

\section{KNOWLEDGE BUILDING PEDAGOGY AND THEORY}

Scardamalia (2002) and Scardamalia and Bereiter (2006) presented 12 principles that altogether describe Knowledge Building as a principle-based pedagogy and that are set forth to make knowledge creation more accessible to teachers and students. These 12 principles frame Knowledge Building as an idea-centered pedagogy with students as epistemic agents, creating knowledge through engaging in complex socio-cognitive interactions. These principles include (Scardamalia, 2002):

Real Ideas and Authentic Problems: Students identify problems that arise from their efforts to understand the world and pursue sustained creative work surrounding them.

Improvable Ideas: Ideas are treated as improvable rather than simply accepted or rejected; students work continuously to improve the explanatory power, coherence, and utility of ideas.

Epistemic Agency: Students set goals, assess their work, engage in long-range planning, monitor idea coherence, use contrasting ideas to spark and sustain knowledge advancement, and engage in high-level knowledge work normally left to the teacher.

Collective Responsibility for Community Knowledge: All participants are legitimate contributors to community goals and take high-level responsibility for advancing the community's knowledge, not just for their individual learning.

Democratizing Knowledge: All participants are empowered as legitimate contributors to the shared goals; all take pride in knowledge advances of the community. Diversity and divisional differences are viewed as strengths rather

than as leading to separation along knowledge have/havenot lines.

Idea Diversity: Knowledge advancement depends on the diversity of ideas, just as the success of an ecosystem depends on biodiversity. To understand an idea is to understand the ideas that surround it, including those that stand in contrast to it.

Knowledge Building Discourse: Students engage in discursive practices that not only share but transform and 
advance knowledge, with problems progressively identified and addressed and new conceptualizations built.

Rise Above: Students work with diverse ideas in complex problem spaces; they transcend trivialities and oversimplifications and work toward more inclusive principles and higher level formulations of problems.

Constructive Use of Authoritative Sources: Participants access and critically evaluate authoritative sources and other information. They use these sources to support and refine their ideas, not just to find the answer.

Pervasive Knowledge Building: Knowledge Building is not confined to particular occasions or subjects but pervades mental life- in and out of school and across contexts.

Symmetric Knowledge Advance: Expertise is distributed within and between communities and team members, with knowledge exchange and construction reflecting the understanding that "to give knowledge is to get knowledge." Embedded and Transformative Assessment: Assessment is integral to Knowledge Building and helps to advance knowledge through identifying advances, problems, and gaps as work proceeds. (pp. 9-12)

In such a community, students are encouraged to advance community knowledge through participation in progressive discourse (Beretier, 1994; Bereiter \& Scardamalia, 1993) and contribute to the community knowledge and a shared knowledge objective (Bereiter, Scardamalia, Cassells, \& Hewitt, 1997). In essence, in Knowledge Building, knowledge is viewed as a social product with students taking collective responsibility for the state of public knowledge and continual idea improvement (Bereiter, 2002; Scardamalia, 2002; Scardamalia \& Bereiter, 2006). Enculturating students to the knowledge building culture "captures the natural human tendency to play creativity with ideas and expands it the unnatural human capacity to exceed the boundaries of what is known and knowable- to exceed the expectations rather than settle into routines" (scardamalia, 2002, p. 78).

The exponential growth of Web 2.0 applications has facilitated the formation of such collaborative networks. The most widely used environment to support Knowledge Building and create collaborative networks in education settings is Knowledge Forum ${ }^{\circledR}$ (https://kf.utoronto.ca) - a web-based discourse medium specifically designed to support production and refinement of community knowledge to advance understanding of the world and effective action through social interaction. Knowledge Forum with its specific design provides opportunities for students to act as knowledge workers in an open space (Scardamalia, 2004).

\section{METHODS AND PLAN of ANALYSIS}

'The primary datasets for this study include a Grade 5 classes within Toronto District School Board (TDSB). Students explored science through Knowledge Forum. In order to examine if students exceeded the science expectations and criss-crossed other STEM disciplines, the study extracts corpus from the Ontario Grade 5 Science, Technology, and Mathematics Curriculum and created a word list. These words served as "expert vocabulary" determine the extent to which students were using expert vocabulary. The study utilizes student's discourse analysis to understand online written discourse notes in Knowledge Forum, which examines how students knowledge demonstrates understanding of the curriculum expectations, as well as if students utilize these "expert words." The study adopts KBDeX (Knowledge Building Discourse eXplorer) (Oshima, Oshima, \& Matsuzawa 2012) to examine if students criss-crossed the STEM domains, through student's discourse usage against the "expert" corpus from Science, Technology, Mathematics, Engineering.

\section{References}

Bereiter, C. (1994). Implications of postmodernism for science, or, science as progressive discourse. Educational Psychologist, 29(1), 3-12.

Bereiter, C. (2002). Education and mind in the knowledge age. Mahwah, NJ: Erlbaum.

Bereiter, C., \& Scardamalia, M. (1993). Surpassing ourselves: an inquiry into the nature and implications of expertise. Chicago: Open Court.

Bereiter, C., Scardamalia, M., Cassells, C., \& Hewitt, J. (1997). Postmodernism, knowledge building, and elementary science. The Elementary School Journal, 97(4), 329.

Oshima, J., Oshima, R., \& Matsuzawa, Y. (2012). Knowledge Building Discourse Explorer: A Social Network Analysis Application for Knowledge Building Discourse. Educational Technology Research and Development, 60, 903-921.

Scardamalia, M. (2002). Collective cognitive responsibility for the advancement of knowledge. In B. Smith (Ed.), Liberal education in a knowledge society (pp. 67-98). Chicago, IL: Open Court.

Scardamalia, M., \& Bereiter, C. (2006). Knowledge building: Theory, pedagogy, and technology. In R. K. Sawyer (Ed.), The Cambridge handbook of the learning sciences (pp. 97-115). Cambridge University Press.

Scardamalia, M., \& Bereiter, C. (2016). Creating, CrissCrossing, and Rising Above Idea Landscapes. In: Huang, R.H., Kinshuk, A., Price, J.K. (eds.) ICT in Education in Global Context: Comparative Reports of K-12 Schools Innovation, (pp. 3-17.) Springer-Verlag, Berlin.

Van de Walle, J. A., Folk, S., Karp, K. S., \& Bay-Williams, J. M. (2014). Elementary and Middle School Mathematics: Teaching Developmentally. Toronto: Pearson Canada Inc. 